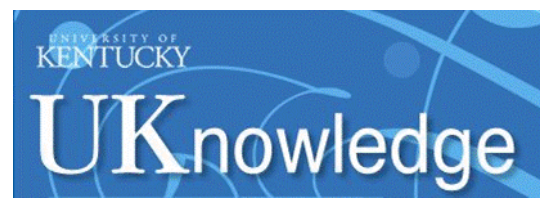

University of Kentucky

UKnowledge

$9-2015$

\title{
Adolescent Developmental Assets and Service Leadership
}

Daniel T. L. Shek

University of Kentucky

Cecilia M. S. Ma

The Hong Kong Polytechnic University, China

Ting Ting Liu

Wuhan University, China

Follow this and additional works at: https://uknowledge.uky.edu/pediatrics_facpub

Part of the Pediatrics Commons

Right click to open a feedback form in a new tab to let us know how this document benefits you.

\section{Repository Citation}

Shek, Daniel T. L.; Ma, Cecilia M. S.; and Liu, Ting Ting, "Adolescent Developmental Assets and Service Leadership" (2015). Pediatrics Faculty Publications. 205.

https://uknowledge.uky.edu/pediatrics_facpub/205

This Article is brought to you for free and open access by the Pediatrics at UKnowledge. It has been accepted for inclusion in Pediatrics Faculty Publications by an authorized administrator of UKnowledge. For more information, please contact UKnowledge@lsv.uky.edu. 


\section{Adolescent Developmental Assets and Service Leadership}

Digital Object Identifier (DOI)

https://doi.org/10.1515/ijdhd-2015-0408

\section{Notes/Citation Information}

Published in International Journal on Disability and Human Development, v. 14, no. 3, p. 275-283.

(C) 2015 Walter de Gruyter GmbH, Berlin/Boston

The copyright holders have granted the permission for posting the article here. 


\section{Daniel T.L. Shek*, Cecilia M.S. Ma and Ting Ting Liu \\ Adolescent developmental assets and service leadership}

DOI 10.1515/ijdhd-2015-0408

Received April 14, 2014; accepted June 14, 2014; previously published online August 27, 2015

\begin{abstract}
In the field of positive youth development, it is generally asserted that developmental assets or positive youth development qualities contribute to positive adolescent developmental outcomes. In the context of training for service leadership, it is argued that the promotion of developmental assets would help university students develop the foundational competence of service leaders. In this paper, the lesson plan of Lecture Eleven in a course entitled "Service Leadership" run in The Hong Kong Polytechnic University is discussed. In the lecture, four developmental assets related to positive identity (self-esteem, self-efficacy, purpose in life and optimism about the future) proposed by Peter Benson are presented. In addition, the possible contribution of different developmental assets to the development of service leadership is highlighted. Moreover, students are encouraged to reflect on their self-identity and explore effective ways to promote their positive self-image.
\end{abstract}

Keywords: developmental assets; internal assets; positive youth development qualities; positive self-identity.

*Corresponding author: Daniel T.L. Shek, PhD, FHKPS, BBS, SBS, JP, Chair Professor of Applied Social Sciences, Faculty of Health and Social Sciences, Department of Applied Social Sciences, The Hong Kong Polytechnic University, Room HJ407, Core H, Hunghom, Hong Kong, P.R. China, E-mail: daniel.shek@polyu.edu.hk; Center for Innovative Programs for Adolescents and Families, The Hong Kong Polytechnic University, Hong Kong, P.R. China; Department of Social Work, East China Normal University, Shanghai, P.R. China; Kiang Wu Nursing College of Macau, Macau, P.R. China; and Division of Adolescent Medicine, Department of Pediatrics, Kentucky Children's Hospital, University of Kentucky College of Medicine, Lexington, KY, USA

Cecilia M.S. Ma: Department of Applied Social Sciences, The Hong Kong Polytechnic University, Hong Kong, P.R. China

Ting Ting Liu: Department of Sociology, Wuhan University, Wuhan, P.R. China

\section{Introduction}

In contrast to the mainstream child and adolescent developmental theories that have a strong emphasis on adolescent developmental problems, a positive youth development approach focuses on the potentials and abilities of children and adolescents. According to theorists adhering to the positive youth development approach, positive youth development constructs or developmental assets are intimately related to adolescent developmental outcomes. The framework of developmental assets is composed of a set of contextual and individual "building blocks" that have been empirically demonstrated to enhance the positive development outcomes of children and adolescents [1, 2]. Serving as a theoretical and practical reference for attempts in promoting youth development, the framework based on developmental assets reflects the primary socialization processes that happen in the second decade of life that are crucial to one's successful transition to adulthood and future development [3].

According to Benson [3], there are 40 important developmental assets that are conducive to the healthy development of young people. These 40 developmental assets are divided into two categories - external assets and internal assets. As far as external assets are concerned, there are four domains involving 20 developmental assets. These include support (family support, positive family communication, other adult relationships, caring neighborhood, caring school climate and parent involvement in schooling), empowerment (youth valued by the community, youth as resources, services to others and safety), boundaries and expectations (family boundaries, school boundaries, neighborhood boundaries, adult role models, positive peer influence and high expectations) and constructive use of time (creative activities, youth programs, religious community and time at home). Likewise, internal assets also have four domains involving 20 developmental assets. These include commitment to learning (achievement motivation, school engagement, home work, bonding to school and reading for pleasure), positive values (caring, equality and justice, integrity, honesty, responsibility and restraint), social competencies 
(planning and decision-making, interpersonal competence, cultural competence, resistance skills and peaceful conflict resolution) and positive identity (personal power, self-esteem, sense of purpose and positive view of personal future). Details of the taxonomy of the 40 developmental assets of youth can be found from the related publications in the field [3-6].

There is rich evidence supporting the notion that developmental assets can lead to a wide range of positive outcomes in young people. Generally speaking, adolescents with more developmental assets have less risky behaviors (e.g. violence, substance abuse), more positive development outcomes (e.g. leadership, prosocial behaviors) and better resilience [6]. As a service leader is defined as one who possesses leadership competencies, moral character and a caring disposition that enable him/ her to provide quality personal service to everyone he/she comes into contact with [7], the positive consequences brought by developmental assets can directly constitute the attributes that are vital to a service leader.

Among the eight categories of developmental assets proposed by Benson, positive identity can be regarded as an important one. Conceptually, it includes self-esteem, self-efficacy, purpose in life and optimism about future. For self-theorists, self-esteem is an important element governing the lives of adolescents. Self-efficacy is also emphasized by social learning theorists. According to Bandura [8], "people make causal contributions to their own functioning through mechanisms of personal agency" (p. 118). Self process heavily mediates the environmental influences on human action and guides the reaction on environments via affecting individuals' selection and construction of environments [8]. However, existential theorists emphasize purpose in life. According to Victor Frankl [9], existential vacuum is a basic existential problem that leads to problem behavior. Finally, optimism is another attribute influencing human behavior in positive psychology.

According to the Hong Kong Institute of Service Leadership and Management (SLAM) curriculum framework, service leadership can take place in three realms: self, others and systems, and leadership in self involves self-serving efforts aimed at ethically improving one's competencies, abilities and willingness to help satisfy the needs of others [7]. As positive self-concept has been demonstrated to be important capital of one's constant development [10] that would lead to increased abilities and willingness to serve others, the four assets about positive identity are naturally included in the framework of self-leadership. Hence, positive identity is closely associated with service leadership via directly motivating self-leadership and providing critical paths to leadership in others and systems. This also explains the expected learning outcomes, as stated in the SLAM curriculum framework that the learners should be instilled with "the desire and motivation to acquire and habitually seek to improve a strong positive repertoire of developmental assets, especially a sense of control over the 'things that happen to me', a sense of high self-esteem and efficacy, a sense of purpose and a sense of optimism about the future" [7]. Therefore, there is an obvious need to include developmental assets in connection with the positive identity domain in the service leadership curriculum.

"Service Leadership" is a newly launched general education subject at The Hong Kong Polytechnic University that aims to cultivate adolescent developmental assets in university students so that students can become competent service leaders in the future. In the second term of the 2012/13 academic year, the subject was offered on a pilot basis in which 14 2-h lectures were designed. As service leadership is quite a new concept in the university curriculum in Hong Kong, the demonstration of such lessons would not only make a documentation of the course but also help colleagues in field to refine the curriculum. In the following, the detailed lecture content of Lecture Eleven, together with the rationales behind the curriculum design and the activities used, is presented.

\section{Overview of the lecture}

Lecture Eleven introduces the concepts and positive influences of developmental assets, and their relationships with service leadership. As positive identity is an important anchor in adolescent development, the focus of this lecture is placed on the four assets constituting positive identity (i.e. self-esteem, self-efficacy, purpose in life and optimism about the future). Strategies for promoting the development of these developmental assets are also recommended in this lecture. As a 1-h group project presentation session is scheduled in Lecture Eleven, which constitutes part of the course assessment, the duration of the lecture is set as $1 \mathrm{~h}$. There are four parts of the lecture content: 1) the nature of developmental assets; 2) positive identity as a developmental asset, which includes the components of self-esteem, self-efficacy, purpose in life and optimism about the future; 3 ) positive identity and service leadership; and 4) conclusions and reflections. Two activities are designed for this lecture to facilitate students' learning and are scheduled after the first and second parts, respectively. 
It is expected that after attending this lecture, students are able to 1) understand the concepts of developmental assets related to the internal asset of positive identity proposed by Peter Benson; 2) comprehend the meanings of four assets of positive identity: self-esteem, self-efficacy, purpose in life and optimism about future; 3 ) appreciate the importance of positive identity and its relationship with service leadership and 4) reflect on one's self-concept and explore effective ways to promote positive self-identity.

\section{Content of the lecture: part I: what are developmental assets?}

As a start, the meaning of "asset" is explained to help students form the idea that assets are desirable things or qualities that help them succeed or deal with problems. Hence, developmental assets could be understood as valuable individual qualities that are helpful to their development. Developmental assets commonly refer to experiences, relationships, knowledge, skills and values that can promote youth developmental outcomes [4, 11]. Following this conception, the developmental assets framework is composed of 40 assets, and the categorization of related assets by Peter Benson is explained. Among the eight categories mentioned previously, positive identity that contains the four components is highlighted with explanations on its essential role in service leadership.

\section{Activity 1: assessing self-esteem and self-efficacy}

Two activities are scheduled in Lecture Eleven to facilitate and consolidate students' learning. The first one is a questionnaire assessment focusing on self-esteem and self-efficacy. The questionnaire is composed of 20 items, including 10 items from the Rosenberg Self-esteem Scale [12] and 10 items from the General Self-efficacy Scale [13]. It is arranged before the second part of lecture to help students form some basic ideas and awareness of their self-evaluation in terms of self-esteem and self-efficacy, which is supposed to facilitate their learning of the concepts in the following section in which the assets are introduced.

The students are instructed to calculate their scores by adding up the scores in each item after they have completed the questionnaire. Then the teacher invites several students to share their results of the assessment and explain the levels of self-esteem and self-efficacy indicated by the scores. Some questions can guide students' sharing, such as "Do you think the scores accurately reflect your levels of self-esteem and selfefficacy?", "Do you think you are a person with high self-esteem and self-efficacy?", "Can you share some personal examples in terms of these aspects?" This activity is wrapped up by emphasizing that self-esteem and self-efficacy are valuable attributes contributing to individual development.

\section{Part II: positive identity: self-esteem, self- efficacy, purpose in life and optimism about future}

The second part covers the four developmental assets related to positive identity, including their meanings and positive effects. Comparison between self-esteem and self-efficacy is also provided to help students identify the commonalities and differences between the two concepts. First, it is introduced that self-esteem is the extent to which one customarily believes himself or herself competent, successful, significant or worthy [14]. Irrespective of their beliefs about their abilities, skills and other characteristics, individuals with high selfesteem generally feel good about themselves, whereas those with low-self-esteem tend to feel bad about themselves, even if they conceive themselves as highly efficacious [15]. Acting as an overall judgment of oneself, self-esteem can influence one positively in many ways. It was found that people with higher self-esteem usually have a stronger sense of personal locus of control and act more independently. As higher self-esteem means higher confidence towards self, it produces more courage for one to attempt new tasks and bear frustrations. Additionally, higher levels of self-esteem were found to be related to a greater willingness to assume positions of leadership [16, 17]. This part of the lecture helps students raise their awareness of self-esteem as well as the positive influences on their lives.

The second asset is self-efficacy, which is conceived as a belief in one's capabilities to set goals and a belief that one possesses the necessary competencies to achieve the goals [18]. Evidence consistently shows that selfefficacy can lead to a series of outcomes that promote one's performance toward the accomplishment of tasks. Compared with others, people with higher self-efficacy tend to set higher goals or select more challenging settings, make more effort and persist longer to achieve the goals and view difficulties and setbacks as challenges to 
be overcome $[16,17,19]$. According to Bandura, there are four major processes through which self-efficacy produces diverse effects, including cognitive, motivational, affective and selective processes $[8,18]$.

To help students understand the mechanism of selfefficacy and form awareness of their own self-efficacy, the four processes are presented: 1) setting goals - one compares his/her personal standards with the level of his/her performance, with those perceiving higher levels of personal capacities setting more challenging goals; 2) anticipating the attainment of goals - one anticipates the likely outcomes by estimating what actions are required, how much effort should be expended, and how long they need to persevere, with those who have stronger beliefs in their capabilities would exert greater effort and persist longer; 3) developing passion for the task - one develops motivation toward the achievement of goals or experiences stress due to perceptions of his/her own coping capabilities, those having a higher sense of efficacy would develop higher passion and lower anxiety; 4) selecting activities and environment one selects activities and situations one thinks oneself capable of, but avoids those exceeding their coping capabilities, with those who are more confident in personal efficacy undertaking more challenging activities and environments [20].

As self-esteem and self-efficacy are both concepts about self-evaluation and usually interrelated, which may create confusions in students, there is a need to lead them to differentiate between the two concepts. It is further explained that while self-esteem captures more of an affective evaluation of or feeling regarding the self, self-efficacy captures more of a motivational belief or a judgment regarding task capabilities [21]. Examples of individuals with high self-esteem and low self-efficacy and individuals with low self-esteem and high selfefficacy are provided to assist students' comprehension. In addition, discussion of what the appropriate levels of self-esteem and self-efficacy are is initiated to provoke critical thinking in the students. Students are led to think about their performance when their self-evaluations are too low, such as a lack of confidence and persistence toward goals. In addition, students are encouraged to consider the negative influences when the evaluations are too high, such as vulnerability to non-productive or counter-productive persistence and inadequate preparation because of underestimation of difficulties [22, 23]. The discussion is wrapped up with recommendations for developing optimum levels of self-esteem and self-efficacy, which would most encourage one to tackle challenging tasks and seek positive development.
The third asset highlighted in the lecture is purpose in life. Human behavior is motivated by the inborn urge to search for meaning [9]. When a person fails to find meaning in life or perceives a vacuum of meaning in personal existence, he/she is confronted by existential frustration [24]. Empirical evidence has shown clearly the association between people's purpose in life and mental health, suggesting that having meaningful purpose in life predicts psychological well-being, while a lack of meaning in life is accompanied by a series of psychological and behavioral problems, such as depression, substance abuse and suicide [24-27].

After highlighting several questions that inspire students to have a quick reflection on whether they perceive their life as meaningful and what the meaning is, this section then introduces the fundamental tenets of Frankl's theory on purpose in life. First, life holds a potential meaning under any conditions, even the most miserable ones. Second, our will to find meaning in life is the primary motivation for living, and each of us has to fulfill the meaning for ourselves. Third, we have freedom to find meaning in what we experience and choose our attitude in any given set of circumstances [28, 29]. Students will also learn the three approaches to discovering meaning in life, as suggested by Frankl: 1) by creating a work or doing a deed, as devoting ourselves to a task or a cause bigger than us creates meaning in our lives; 2) by experiencing something such as goodness, truth or beauty or experiencing someone, as "love is the ultimate and highest goal which man can spire” [9, p. 49]; 3) by formulating a right attitude toward unavoidable suffering, as rising above suffering and transcending tragedies and turning them into triumphs bring us meaning $[9,29]$. The section discussing purpose in life is wrapped up with several reflective questions, such as "What drove you to attend the class of 'Service Leadership'?", "What motivated you to bounce back from the last frustration?", and "What made you help a friend without expecting a reward?"

The last asset to be included is optimism, which refers to a generally positive attitude or disposition that good things will happen independently of one's ability [30]. Different from self-esteem, which is a general evaluation of self, and self-efficacy, which is a task-specific belief in self, optimism indicates a generalized positive outcome expectancy toward the future [16]. Literature shows that optimists tend to take credit for favorable events in their lives and therefore have higher morale and confidence to achieve goals and are more able to cope with stressors that arise on the path to successful performance [19]. In addition, individuals with higher optimism are more likely to recover and improve after failure, as they possess a 
positive attribution style that is characterized by attributing "success to internal, stable and global causes or failure to external, unstable and specific causes" [16, p. 268].

\section{Activity 2: what do I live for?}

The second activity takes the form of self-reflection, with the purpose of stimulating students' reflection on the meaning of their lives. Utilizing the story of the movie "Cast Away", in which the hero successfully survives on a lonely island after an air disaster, motivated by the hope to meet his fiancée again, the activity engages students by requesting that they imagine they experience the same situation and reflect on their purpose in life that could support them in surviving tragedy. This activity is arranged after the end of the second part of the lecture to direct students to realize the power of meaningful purpose in life and be aware of the meaning in their own lives.

In this activity, the teacher briefly introduces the plot of "Cast Away" and distributes a worksheet (see Appendix 1) to every student. Students are required to read the story in the worksheet first, and then the teacher plays a 2.5-min movie trailer to help students get into the mood quickly. After watching the video, students are requested to imagine that if they were in the same situation, what beliefs/reasons they would hold onto to survive and then to write down at least three in the specified place. The teacher can invite several students to share their responses to the worksheet in class. The teacher's self-disclosure of personal thoughts or reflections is suggested in this activity, which is deemed to be an effective practice in encouraging students' expression. This activity is wrapped up by emphasizing the importance of having meaningful purpose in life, whether in favorable or miserable conditions.

\section{Part III: positive identity and service leadership}

The third part of the lecture addresses the key question of how the four developmental assets of positive identity are related to service leadership. First, students are led to review the typical features of service leadership they have learned in previous lectures. It is recapped that an effective service leader should lead oneself first to optimize their abilities to lead and serve others. In addition, service leadership intrinsically requires the leader to influence the group habitat positively. Different from the traditional leadership style that stresses authority and power more, service leaders should build their leadership through education, trust, respect, inspiration and rolemodeling. Such performance further represents a series of specific actions, such as seeking continuous personal development, nurturing others' growth and boosting group morale.

Second, it is stated that all of the four developmental assets can help to shape one's behavior toward the above-mentioned performance, with their effects promoting different aspects of service leadership. Students are encouraged to think about and discuss the roles of the four assets in leading one to perform in that way, based on their learning of the positive outcomes of the assets in this lecture. Following students' discussion, the teacher will elaborate that people with positive identity commonly possess some attributes, and these attributes could direct a person to behave in certain ways that also outline the behaviors of service leadership. For example, a person with high self-efficacy is normally diligent and perseverant, which would lead him/her to pursue continuous personal development; one who has found meaningful purpose in life tends to be self-motivated and prosocial, and thus would be more willing to empower other people and nurture others' growth; an optimistic person who is passionate and energetic can boost group morale when working with others toward collective goals. A table showing these links is presented in Table 1. Inspired by such a model, students are encouraged to propose further explanations for the possible links between them with support of the scientific literature.

\section{Part IV: conclusions and topics for further reflections}

In the last part, a short conclusion of the lecture is given. Starting with a brief recap of the four developmental assets of positive identity, this part then highlights that 1) these assets are interrelated with each other; 2 ) accumulation of the assets produces the desirable outcomes; and 3) all these assets are not inborn traits but can be developed [21, 31, 32]. Referring to others' experiences, some tips for building positive self-image are suggested to students: 1) engage in an important job or worthwhile work; 2) take responsibility for what you have done or what you are doing; 3) listen to your inner voice; 4) choose the brighter side of things, instead of the darker side; 5) replace criticism with encouragement; and 
Table 1: Relationship between positive identity and service leadership.

\begin{tabular}{lll}
\hline Positive identity & Positive attributes & Effective service leadership \\
\hline Self-esteem & - Independent & - Be willing to assume leader position \\
& - Confident & - Empower followers \\
Self-efficacy & - Persuasive & - Support others' development \\
& - Diligent & - Lead to higher group goals \\
& - Perseverant & - Produce sustainable group progress \\
Meaningful purpose in life & - Thoughtful & - Be trusted by followers \\
& - Resilient & \\
Optimism & - Motivated & - Nurture others' growth \\
& - Thoughtful & - Encourage followers' commitment \\
& - Prosocial & - Be respected by followers \\
& - Enthusiastic & - Strengthen group morale
\end{tabular}

6) focus on what you can do, not what you cannot. Finally, an inspiring quote from Henry David Thoreau, an American author and philosopher, is presented: "If one advances confidently in the direction of his dreams, and endeavors to live the life which he has imagined, he will meet with a success unexpected in common hours". This part ends with a positive statement that "I am a very special, unique, and valuable person. I deserve to feel good about myself" to encourage students to develop a positive self-image.

\section{Discussion}

The above presented a 1-h lecture regarding positive identity and service leadership in a university context. If more time is available, the teacher can cover more content, and here are some possible topics. First, in addition to the work of Peter Benson, the teacher can help students understand that although there are different views on positive youth development qualities in the literature, it is commonly related to competencies in a) self-understanding and cultivating discipline; b) working with others, communicating, cooperating, negotiating and building relationships; c) coping, adapting and being responsible; and d) making good judgments, evaluating, making decisions and problemsolving. Students can also be invited to consider the views of the Collaborative for Academic, Social and Emotional Learning (CASEL: http://www.casel.org) that "social and emotional learning" (SEL) covers emotional recognition and management skills, cultivation of care and concern for others, responsible decision-making, positive relationship building and effective handling of situations. With reference to the specific assets to be developed, Weissberg and O’Brien [33] suggested five core social-emotional competencies to be targeted in positive youth development programs: self-awareness, social awareness, self-management, relationship skills and responsible actions. Graczyk et al. [34] also argued that promotion of social and emotional learning of adolescents (SEL) can serve as a unifying framework that can integrate the risk and protective factors paradigm and the competence enhancement paradigm.

In addition to materials on different frameworks on positive youth development and developmental assets, the teacher can help students appreciate the benefits of developing developmental assets. One example is the Project P.A.T.H.S. in Hong Kong, which is a positive youth development program designed for junior secondary school students. Using different types of evaluation strategies, findings consistently showed that different stakeholders had positive evaluations of the project. Compared to the control participants, students who had joined the program showed more positive holistic development and lower levels of adolescent risk behavior [35, 36]. Further supporting evidence was found for a leadership subject based on positive youth development constructs offered at The Hong Kong Polytechnic University [37-42]. All these suggest that this kind of adolescent development curriculum is worth implementing in university settings. 


\section{Appendix 1}

\section{THE HONG KONG POLYTECHNIC UNIVERSITY DEPARTMENT OF APPLIED SOCIAL SCIENCES APSS2820 Service Leadership}

Lecture Eleven: Developmental Assets and Service Leadership:

Self-Esteem, Self-Efficacy, Purpose in Life, and Optimism about the Future

Activity 2: What Do I Live for?

Story: It was unfortunate that Chuck's airplane crashed when flying through a violent storm, and he was the only one to escape the sinking plane alive. He then washed up on an uninhabited island without any communication equipment. The isolation of his location meant that nobody could save him.

The available water and food were not enough for more than 5 days. It seemed Chuck would die soon on this lonely island. However, he disagreed that he was destined to die alone. He remembered the last date with his dearest lover, Kelly and desired to see her again. He knew he had to stay alive. He knew he had to keep breathing...

During the following days, he tried every possible method to sustain his life. He did not give up, even to the point of death time after time. Finally, he was found by a passing cargo ship and returned to his home.

*This story is adapted from the movie "Cast Away"

Imagine that you were Chuck and were cast away on a desert island. What reasons/beliefs would support you in hanging onto life despite such a miserable situation?

Please write down at least three things you live for:

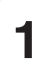

2

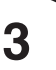

4

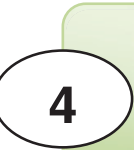




\section{References}

1. Stevens H, Wilkerson K. The developmental assets and ASCA's national standards: a crosswalk review. Prof School Couns 2010;13:227-33.

2. Bagdi A, Vacca J. Supporting early childhood social-emotional well being: the building blocks for early learning and school success. Early Child Educ J 2005;33:145-50.

3. Benson PL. All kids are our kids: what communities must do to raise caring and responsible children and adolescents. San Francisco, CA: Jossey-Bass, 2006.

4. Benson PL, Leffert N, Scales PC, Blyth DA. Beyond the "village" rhetoric: creating healthy communities for children and adolescents. Appl Dev Sci 1998;2:138-59.

5. Scales PC, Benson PL, Leffert N, Blyth DA. Contribution of developmental assets to the prediction of thriving among adolescents. Appl Dev Sci 2000;4:27-46.

6. Leffert N, Benson PL, Scales PC, Sharma AR, Drake DR, Blyth DA. Developmental assets: measurement and prediction of risk behaviors among adolescents. Appl Dev Sci 1998;2:209-30.

7. Chung P. Hong Kong Institute of Service Leadership and Management curriculum framework. Hong Kong: Hong Kong Institute of Service Leadership and Management, 2011.

8. Bandura A. Perceived self-efficacy in cognitive development and functioning. Educ Psychol 1993;28:117-48.

9. Frankl V. Man's search for meaning: an introduction to logotherapy, 3rd ed. New York, NY: Touchstone, 1984.

10. Bornstein MH, Davidson L, Keyes CL, Moore KA, editors. Well-being: positive development across the life course. New York, NY: Psychology Press, 2012.

11. Arturo Sesma J, Mannes M, Scales PC. Positive adaptation, resilience, and the developmental asset framework. In: Goldstein S, Brooks RB, editors. Handbook of resilience in children. New York: Kluwer Academic/Plenum, 2005:281-96.

12. Rosenberg M. Society and the adolescent self-image. Princeton: Princeton University Press, 1965.

13. Schwarzer R. Measurement of perceived self-efficacy: psychometric scales for cross-cultural research. Berlin: Freien Universität, 1993.

14. Coopersmith S. Coopersmith self esteem inventory. Palo Alto: Consulting Psychologists Press, 1981.

15. Brown JD. The self. New York: McGraw-Hill, 1998.

16. Chemers MM, Watson CB, May ST. Dispositional affect and leadership effectiveness: a comparison of self-esteem, optimism, and efficacy. Pers Soc Psychol B 2000;26:267-77.

17. Conner M, Norman P. Predicting health behaviour: research and practice with social cognition models. Buckingham: Open University Press, 1995.

18. Bandura A. Self-efficacy: the exercise of control. New York: WH Freeman, 1997.

19. Toor S, Ofori G. Positive psychological capital as a source of sustainable competitive advantage for organizations. J Constr Eng M 2010;136:341-52.

20. Bandura A. Self-efficacy. In: Ramachaudran VS, editor. Encyclopedia of human behavior. New York, NY: Academic Press, 1994:71-81.

21. Chen G, Gully SM, Eden D. General self-efficacy and self-esteem toward theoretical and empirical distinction between correlated self-evaluations. J Organ Behav 2004;25:375-95.
22. Crocker J, Brook AT, Niiya Y, Villacorta M. The pursuit of selfesteem: contingencies of self-worth and self-regulation. J Pers 2006;74:1749-71.

23. McCormick J, McPherson G. The role of self-efficacy in a musical performance examination: an exploratory structural equation analysis. Psychol Music 2003;31:37-51.

24. Crumbaugh JC, Maholick LT. An experimental study in existentialism: the psychometric approach to Frankl's concept of noogenic neurosis. J Clin Psychol 1964;20:200-7.

25. Shek DT. Meaning in life and psychological well-being: an empirical study using the Chinese version of the Purpose in Life questionnaire. J Genet Psychol 1992;153:185-200.

26. Harlow LL, Newcomb MD, Bentler PM. Depression, self-derogation, substance use, and suicide ideation: lack of purpose in life as a mediational factor. J Clin Psychol 1986;42:5-21.

27. DuRant RH, Getts A, Cadenhead C, Emans SJ, Woods ER. Exposure to violence and victimization and depression, hopelessness, and purpose in life among adolescents living in and around public housing. J Dev Behav Pediatr 1995;16:233-7.

28. Marshall M, Marshall E. Logotherapy revisited: review of the tenets of Victor Frankl's logotherapy. Canada: CreateSpace, 2012.

29. Dhiman S. Personal mastery: our quest for self-actualization, meaning, and highest purpose. Interbeing 2007;1:25-35.

30. Dunavold P. Happiness, hope, and optimism. Available at: http://www.csun.edu/ vcpsy00h/students/happy.htm. Accessed: 18 Sep 2012.

31. Hannah ST, Woolfolk RL, Lord RG. Leader self-structure: a framework for positive leadership. J Organ Behav 2009;30:269-90.

32. Peterson SJ, Balthazard PA, Waldman DA, Thatcher RW. Are the brains of optimistic, hopeful, confident, and resilient leaders different? Organ Dyn 2008;37:342-53.

33. Weissberg RP, O' Brien MU. What works in school-based social and emotional learning programs for positive youth development. Ann Am Acad Pol Soc Sci 2004;591:86-97.

34. Graczyk PA, Weissberg RP, Payton JW, Elias MJ, Greenberg MT, Zins JE. Criteria for evaluating the quality of school-based social and emotional learning programs. In: Reuven BO, Park DA, editors. The handbook of emotional intelligence: theory, development, assessment, and application at home, school and in the workplace. San Francisco, CA: Jossey-Bass, 2000:391-409.

35. Shek DT, Sun RC. The Project P.A.T.H.S. in Hong Kong: development, training, implementation, and evaluation. J Pediatr Adolesc Gynecol 2013;26:S2-9.

36. Shek DT, Sun RC, editors. Development and evaluation of positive adolescent training through holistic social programs (P.A.T.H.S.). Berlin: Springer, 2013.

37. Shek DT, Sun RC. Promoting leadership and intrapersonal competence in university students: what can we learn from Hong Kong? Int J Disabil Hum Dev 2012;11:221-8.

38. Shek DT, Sun RC. Promoting psychosocial competencies in university students: evaluation based on a one group pretestposttest design. Int J Disabil Hum Dev 2012;11:229-34.

39. Shek DT, Sun RC. Process evaluation of a positive youth development course in a university setting in Hong Kong. Int J Disabil Hum Dev 2012;11:235-41. 
40. Shek DT, Sun RC, Tsien-Wong TB, Cheng CT, Yim HY. Objective outcome evaluation of a leadership and intrapersonal development subject for university students. Int J Disabil Hum Dev 2013;12:221-7.

41. Shek DT, Sun RC. Post-course subjective outcome evaluation of a course promoting leadership and intrapersonal development in university students in Hong Kong. Int J Disabil Hum Dev 2013;12:193-201.

42. Shek DT. Promotion of holistic development in university students: a credit-bearing subject on leadership and intrapersonal development. Best Pract Ment Health 2013;9:47-61. 